\title{
Factors predicting outcome of vitrectomy for diabetic macular oedema: results of a prospective study
}

\author{
S P Shah, M Patel, D Thomas, S Aldington, D A H Laidlaw
}

Br J Ophthalmol 2006;90:33-36. doi: 10.1136/bjo.2005.072934

Aim: To determine preoperative demographic, clinical, and optical coherence tomography (OCT) factors which might predict the visual and anatomical outcome at 1 year in patients undergoing vitrectomy and inner limiting membrane peel for diabetic macular oedema (DMO).

Methods: A prospective, interventional case series of 33 patients who completed 1 year follow up. Measurements were taken preoperatively and at 1 year. Outcome measures were logMAR visual acuity (VA) and OCT macular thickness. A priori explanatory variables included baseline presence of clinical and/or OCT signs suggesting macular traction, grade of diabetic maculopathy, posterior vitreous detachment, fluorescein leakage and ischaemia on angiography, presence of subretinal fluid, and peroperative indocyanine green (ICG) use.

Results: 33 patients completed 1 year follow up. On average VA deteriorated by $0.035 \log M A R(p=0.40)$. Macular thickness significantly improved by a mean of $139 \mu \mathrm{m}$ (95\% Cl; 211 to $67, \mathrm{p}<0.001)$. Patients with evidence of clinical and/or OCT macular traction significantly improved logMAR acuity (logMAR improvement $=0.08$ ) compared with patients without traction (logMAR deterioration 0.11, $p=0.01$ ). Presence of subretinal fluid significantly predicted worse postoperative result $(p=0.01)$

Conclusion: On average, patients showed a statistically significant improvement in central macular thickness following treatment but a marginal acuity worsening. Presence of subretinal fluid on OCT is hypothesised to be exudative rather than tractional in nature. The visual benefit of vitrectomy for DMO in this study was limited to patients who exhibit signs of macular traction either clinically and/or on OCT.

$\mathrm{T}$ he majority of published reports ${ }^{1-35}$ regarding vitrectomy for diabetic macular oedema (DMO) are retrospective with varying inclusion criteria, methodology, and follow up. Most studies have suggested that the procedure is effective, particularly in those with clinically evident signs of a taut thickened posterior hyaloid $\left(\mathrm{TTPH}^{1}\right)$. In the first published randomised controlled trial (RCT) on this subject we found that vitrectomy with internal limiting membrane (ILM) peeling did not improve the visual acuity (VA) of patients with a clinically attached but otherwise normal posterior hyaloid. ${ }^{24}$ To investigate whether there are subgroups within which vitrectomy is an effective intervention we have prospectively studied a cohort of patients, all with 1 year follow up, who underwent vitrectomy for chronic DMO.

\section{PATIENTS AND METHODS}

Ethics approval was obtained (EC 00/004). Patients included were over 21 years of age with diffuse or diffuse and focal
DMO in an eye that had already received one or more grid laser treatments no less than 3 months previously. VA of Snellen $6 / 12$ or worse and the ability to give informed consent was required. Exclusion criteria were acuity impairing ocular co-morbidity, active proliferative retinopathy, uncontrolled hypertension (blood pressure >140/95) or severe renal impairment. VA was measured in logMAR using a standardised methodology. ${ }^{24}$

The vitreous, macula, and vitreomacular interface were examined clinically (DAHL) for the features of a PVD, TTPH, and epiretinal membrane (ERM). PVD was defined as a Weiss ring or continuous folded layer of optically dense vitreous behind which no normal vitreous structure could be clinically defined. Preoperative colour imaging and fluorescein angiography (FFA) was performed using the standard 30 degree seven field Diabetic Retinopathy Study protocol. ${ }^{36}$

Images were graded by the Retinopathy Grading Centre, London. The presence of haemorrhages, microaneurysms, and exudates in field 2 photographs (macula) were each graded $0-5$ against standardised photographs, ${ }^{37}$ with the results averaged to produce a maculopathy score (0-5). FFAs were graded for ischaemia and leakage. Ischaemia was graded from 0-4: four quadrants were marked out within a 0.5 disc diameter (DD) marker centred on the fovea. Grade 0 meant the foveal avascular zone (FAZ) remained within all the quadrants. FAZ breakout from a quadrant increased the grade by one. The percentage area of leakage was graded between 0 and 5. A central 2 DD marker was placed on the fovea. Grade 0 was no leakage, grade 1 meant up to $20 \%$ of the marker area with leakage; grade 2 meant $20-40 \%$, and so on.

Automated OCT measurements of mean central macular thickness (CMT) based on six radial scans were employed. ${ }^{24}$ OCTs were graded (SS and DAHL) to identify signs suggesting macular traction (retinal surface peaking, epiretinal membrane, and focal or multifocal partial vitreomacular separation) and subretinal fluid (fig 1).

The intervention consisted of a PPV with posterior hyaloid detachment if not present and ILM peeling. ICG staining was conducted on 21 patients. For this purpose aqueous ICG solution (Pulsion) diluted with Alcon BSS to $0.5 \mathrm{mg} / \mathrm{ml}$ was used. All surgery was conducted by one surgeon (DAHL).

Potential predictors examined were presence of macular traction (clinical and/or OCT signs suggesting traction), PVD, maculopathy, ischaemia and leakage grades, SRF, and ICG use. ${ }^{26}{ }^{27}$ Primary outcome measures were (1) best corrected $\log$ MAR VA at 1 year, (2) CMT.

\footnotetext{
Abbreviations: $C M T$, central macular thickness; $D D$, disc diameter; DMO, diabetic macular oedema; ERM, epiretinal membrane; FAZ, foveal avascular zone; FFA, fluorescein angiography; ICG, indocyanine green; ILM, internal limiting membrane; OCT, optical coherence tomography; RCT, randomised controlled trial; TTPH, taut thickened posterior hyaloid; VA, visual acuity
} 


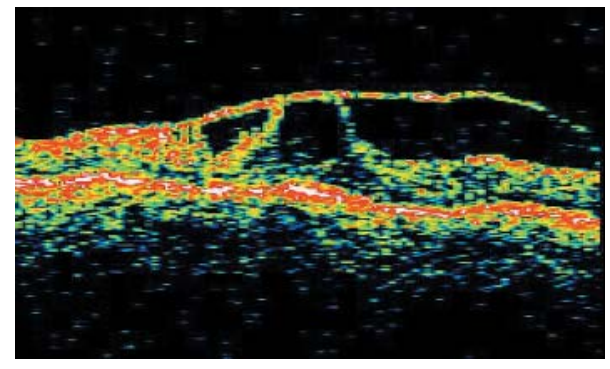

Figure 1 OCT image showing partial vitreomacular separation with multifocal traction.

\section{Statistical analysis}

Inverse normal plots confirmed normal distribution. Paired $t$ tests were used to compare outcome measures. Univariate and multivariate linear regression undertaken with VA (or CMT) difference as the dependent variable in each model. Pairwise pearson correlation coefficients were calculated for VA change against CMT change and for baseline VA against VA change.

\section{RESULTS}

In all, 33 patients forming the study population were followed up for 1 year postoperatively. This includes the 14 previously reported trial patients who completed l year follow up. ${ }^{24}$ Mean age was 65.4 years; there were 14 female patients. Quantitative OCT data were lost on three patients. One set of images was unreadable. Baseline characteristics

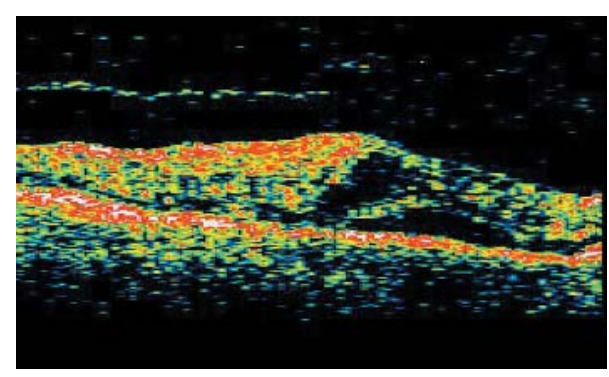

Figure 2 OCT image showing presence of subretinal fluid.

and 1 year outcomes are shown in table 1 . Included in the study were 18 patients with a clinically normal attached posterior hyaloid (of whom four had OCT signs suggestive of traction), six had a TTPH, one had an epiretinal membrane with OCT signs of epiretinal traction, seven had PVD but no clinical or OCT signs suggestive of traction, and one patient had a PVD and clinically normal macular surface but undetermined OCT appearance because of missing qualitative data.

Overall, there was a mean worsening of $+0.035 \log$ MAR (range +0.62 to -0.30 , CI $-0.05,+0.12, \mathrm{p}=0.40$ ). CMT significantly improved from baseline with a reduction of $-139 \mu \mathrm{m}$ (range $-497 \mu \mathrm{m}$ to $+324 \mu \mathrm{m}$, CI -21 to -671 , $\mathrm{p}<0.001$ ), with 17 (57\%) patients having a CMT of less than $300 \mu \mathrm{m}$ at 1 year. No significant correlation was found either between baseline acuity and change in VA $(r=-0.31$, $\mathrm{p}=0.08)$ or VA change and CMT change $(r=0.08, \mathrm{p}=0.63$. $)$

Table 1 Baseline and 1 year characteristics

\begin{tabular}{|c|c|c|c|c|c|c|c|c|}
\hline \multirow[b]{2}{*}{$\begin{array}{l}\text { Age/sex } \\
\text { (years) }\end{array}$} & \multirow[b]{2}{*}{$\begin{array}{l}\text { IOL } \\
(\mathrm{Yes} / \mathrm{No})\end{array}$} & \multirow[b]{2}{*}{$\begin{array}{l}\text { ETDRS } \\
\text { level }\end{array}$} & \multicolumn{2}{|l|}{ VA } & \multicolumn{2}{|l|}{$\mathrm{CMT}^{*}$} & \multirow[b]{2}{*}{$\begin{array}{l}\text { SRFt } \\
\text { (Yes/No) }\end{array}$} & \multirow[b]{2}{*}{$\begin{array}{r}\text { Traction } \ddagger \\
(\text { Yes/No) }\end{array}$} \\
\hline & & & $\begin{array}{l}\text { Baseline } \\
\text { (logMAR) }\end{array}$ & $\begin{array}{l}1 \text { year } \\
\text { (logMAR) }\end{array}$ & $\begin{array}{l}\text { Baseline } \\
(\mu \mathrm{m})\end{array}$ & $\begin{array}{l}1 \text { year } \\
(\mu \mathrm{m})\end{array}$ & & \\
\hline $61 / M$ & $\mathrm{~N}$ & $35 e$ & 0.28 & 0.58 & 417 & 272 & $\mathrm{~N}$ & $\mathrm{~N}$ \\
\hline $71 / \mathrm{F}$ & $\mathrm{N}$ & $47 c$ & 0.30 & 0.30 & 336 & 169 & $\mathrm{~N}$ & $Y$ \\
\hline $65 / M$ & $\mathrm{~N}$ & $53 c$ & 0.32 & 0.22 & & 518 & . & $Y$ \\
\hline $75 / F$ & $\mathrm{~N}$ & $47 d$ & 0.34 & 0.94 & 202 & 131 & $\mathrm{~N}$ & $\mathrm{~N}$ \\
\hline $65 / M$ & $\mathrm{~N}$ & $35 f$ & 0.34 & 0.66 & 324 & 379 & $\mathrm{~N}$ & $\mathrm{~N}$ \\
\hline $45 / M$ & $Y$ & $53 a$ & 0.34 & 0.30 & 237 & 346 & $\mathrm{~N}$ & $Y$ \\
\hline $56 / F$ & $N$ & . & 0.34 & 0.12 & . & . & . & $Y$ \\
\hline $73 / M$ & $Y$ & $61 \mathrm{~b}$ & 0.40 & 0.26 & 476 & 402 & $\mathrm{~N}$ & $\mathrm{~N}$ \\
\hline $52 / M$ & $\mathrm{~N}$ & $61 \mathrm{~b}$ & 0.40 & 0.44 & 411 & 393 & $\mathrm{~N}$ & $\mathrm{~N}$ \\
\hline $54 / M$ & $\mathrm{~N}$ & $47 \mathrm{~b}$ & 0.40 & 1.02 & 575 & 220 & $Y$ & $\mathrm{~N}$ \\
\hline $62 / M$ & $\mathrm{~N}$ & $61 \mathrm{~b}$ & 0.42 & 0.42 & 369 & 294 & $\mathrm{~N}$ & $\mathrm{~N}$ \\
\hline $70 / \mathrm{F}$ & $\mathrm{N}$ & $53 d$ & 0.44 & 0.82 & 355 & 156 & $\mathrm{~N}$ & $\mathrm{~N}$ \\
\hline $72 / F$ & $\mathrm{~N}$ & $47 d$ & 0.44 & 0.64 & 562 & 478 & $\mathrm{~N}$ & $\mathrm{~N}$ \\
\hline $75 / M$ & $\mathrm{~N}$ & $53 d$ & 0.48 & 0.34 & 584 & 134 & $\mathrm{~N}$ & $\mathrm{~N}$ \\
\hline $65 / M$ & $Y$ & $47 a$ & 0.48 & 0.58 & 488 & 579 & $\mathrm{~N}$ & $\mathrm{~N}$ \\
\hline $60 / M$ & $\mathrm{~N}$ & $65 a$ & 0.62 & 0.58 & 660 & 163 & $\mathrm{~N}$ & $Y$ \\
\hline $72 / M$ & $\mathrm{~N}$ & $47 a$ & 0.66 & 0.44 & 338 & 269 & $\mathrm{~N}$ & $Y$ \\
\hline $82 / M$ & $N$ & $47 a$ & 0.74 & 0.50 & 354 & 157 & $\mathrm{~N}$ & Y \\
\hline $63 / F$ & $N$ & $53 a$ & 0.76 & 0.68 & 337 & 364 & $\mathrm{~N}$ & $N$ \\
\hline $75 / M$ & $\mathrm{~N}$ & $65 a$ & 0.78 & 0.78 & 403 & 219 & $\mathrm{~N}$ & $\mathrm{~N}$ \\
\hline $46 / M$ & $\mathrm{~N}$ & $47 \mathrm{~b}$ & 0.80 & 0.70 & 535 & 859 & $Y$ & $\mathrm{~N}$ \\
\hline $46 / M$ & $\mathrm{~N}$ & $65 a$ & 0.80 & 0.78 & 742 & 359 & $\mathrm{~N}$ & $Y$ \\
\hline $63 / M$ & $Y$ & $35 d$ & 0.80 & 1.04 & 698 & 505 & $Y$ & $Y$ \\
\hline $74 / F$ & $Y$ & $47 a$ & 0.84 & 0.68 & 286 & 126 & $\mathrm{~N}$ & $\mathrm{~N}$ \\
\hline $63 / F$ & $\mathrm{~N}$ & $61 a$ & 0.90 & 0.74 & 290 & 179 & $\S$ & $\S$ \\
\hline $80 / F$ & $\mathrm{~N}$ & $47 a$ & 0.98 & 1.52 & 532 & 695 & $Y$ & $\mathrm{~N}$ \\
\hline $63 / M$ & $\mathrm{~N}$ & $61 \mathrm{~b}$ & 1.00 & 1.04 & 589 & 348 & $\mathrm{~N}$ & $\mathrm{~N}$ \\
\hline $64 / F$ & $\mathrm{~N}$ & $65 a$ & 1.00 & 0.86 & 643 & 182 & $\mathrm{~N}$ & $\mathrm{~N}$ \\
\hline $70 / F$ & $N$ & $47 a$ & 1.00 & 1.06 & 617 & 190 & $\mathrm{~N}$ & $\mathrm{~N}$ \\
\hline $75 / F$ & $\mathrm{~N}$ & $61 \mathrm{~b}$ & 1.00 & 1.02 & 670 & & $\mathrm{~N}$ & $Y$ \\
\hline $67 / F$ & $Y$ & $61 \mathrm{~b}$ & 1.06 & 1.14 & 358 & 214 & $\mathrm{~N}$ & $\mathrm{~N}$ \\
\hline $51 / M$ & $\mathrm{~N}$ & $47 a$ & 1.06 & 0.80 & 742 & 548 & $\mathrm{~N}$ & $Y$ \\
\hline $82 / F$ & $\mathrm{~N}$ & $47 d$ & 1.20 & 0.90 & 299 & 252 & $\mathrm{~N}$ & $\mathrm{~N}$ \\
\hline \multicolumn{9}{|c|}{$\begin{array}{l}\text { *CMT, central macular thickness as determined on OCT. } \\
\text { †SRF, subretinal fluid as determined on baseline qualitative OCT assessment. } \\
\text { †Macular traction group defined as patients with a TTPH, ERM and/or OCT signs suggestive of traction. } \\
\text {-Protocol violation logMAR acuity better than } 0.3(6 / 12) \text {. } \\
\text { §OCT image missing for analysis of SRF and macular traction. }\end{array}$} \\
\hline
\end{tabular}


Table 2 Changes in visual acuity with the preoperatively determined risk factors

\begin{tabular}{|c|c|c|c|c|c|}
\hline Variable & No & VA change* & No & VA change* & p Value \\
\hline Overall & $\begin{array}{l}33 \\
\text { Yes }\end{array}$ & +0.04 & & No & 0.40 \\
\hline $\begin{array}{l}\text { Macular traction } \dagger \\
\text { PVD } \\
\text { Ischaemia } \dagger \\
\text { Leakage of }>40 \% \dagger \\
\text { Maculopathy level }>2 / 5 \dagger \\
\text { Subretinal fluid } \\
\text { ICG use }\end{array}$ & $\begin{array}{l}11 \\
9 \\
24 \\
17 \\
24 \\
4 \\
21\end{array}$ & $\begin{array}{l}-0.08 \\
-0.04 \\
+0.03 \\
+0.03 \\
+0.05 \\
+0.33 \\
+0.01\end{array}$ & $\begin{array}{l}21 \\
24 \\
8 \\
15 \\
8 \\
26 \\
12\end{array}$ & $\begin{array}{l}+0.11 \\
+0.06 \\
+0.07 \\
+0.05 \\
-0.01 \\
+0.01 \\
+0.08\end{array}$ & $\begin{array}{l}0.01 \ddagger \\
0.47 \ddagger \\
0.13 \ddagger \\
0.10 \ddagger \\
0.57 \ddagger \\
0.01 \ddagger \\
0.63 \ddagger\end{array}$ \\
\hline
\end{tabular}

There was no difference in baseline vision $(p=0.82)$, CMT $(\mathrm{p}=0.18)$ and presence/absence of pseudophakia $(\mathrm{p}=0.97)$ between groups with and without macular traction. The six patients with a clinical TTPH improved by a mean -0.06 $\log$ MAR (range -0.26 to +0.24$)$ and $-95 \mu \mathrm{m}(-194$ to 109$)$, while the five who had OCT signs of traction but did not have a clinical TTPH showed a mean improvement of -0.1 logMAR (range -0.24 to 0.0 ) and CMT reduction of $-262 \mu \mathrm{m}$ (range $-497 \mu \mathrm{m}$ to $-69 \mu \mathrm{m}$ ). The 22 patients who had neither a clinical TTPH nor traction on OCT had a mean VA deterioration of $+0.11 \log$ MAR (range +0.62 to -0.30 ) but a CMT improvement of $-117 \mu \mathrm{m}$.

The results of the multivariate regression modelling revealed that both macular traction and SRF at baseline significantly predicted visual outcome (table 2). No covariates were found to be statistically significant predictors of CMT outcome.

\section{DISCUSSION}

Vitrectomy has recently been investigated as an alternative treatment to laser photocoagulation. The clinical entity of a TTPH was first described by Lewis et al, ${ }^{1}$ who suggested that the hyaloid in these circumstances exerts tangential traction on the retinal surface inducing or exacerbating oedema and that relief of this traction resulted in visual improvement. Kaiser et al later published OCT data supporting the hypothesis that TTPH is associated with signs of traction. ${ }^{38}$ The importance of OCT imaging is increasingly being recognised and has now revolutionised the clinical analysis of the vitreomacular interface. ${ }^{39-41}$ OCT features suggesting vitreoretinal traction may however occur in the absence of a clinical TTPH. This was the case in four patients included in this study. Massin et al have retrospectively reported an improvement of two lines in 70\% (5/7) of patients with OCT features of traction, compared to only $12.5 \%$ ( $1 / 8)$ rate of two line improvement and a median doubling of the visual angle from $20 / 100$ to $20 / 200$ in seven patients without OCT evidence of traction. ${ }^{7}$ OCT data from prospective stu$\operatorname{dies}^{12} 133435$ all report a reduction in CMT postoperatively; however, correlation of CMT reduction with VA improvement must be made with caution ${ }^{34}$ and we found no evidence of such a relation $(p=0.63)$. Reasons for this may include photoreceptor dysfunction following chronic oedema, multiple laser photocoagulation induced damage, or macular perfusion abnormalities.

Excluding our RCT, 10 other prospective studies, $12131725-293435$ which in total include 178 eyes, have been conducted in this field. The findings suggest that vitrectomy may be beneficial; $100 / 178$ eyes $(56.2 \%$, range $50 \%-78 \%$ ) demonstrated an acuity improvement of two or more lines at final follow up; however, results of the RCT found no statistically or clinically significant difference in acuity or CMT between the control and vitrectomy groups. ${ }^{24}$
The results in this study show 15\% (5/33) and 24\% (8/33), respectively, improving or deteriorating by two or more ETDRS logMAR lines. Patients identified with macular traction had an approximately 1 logMAR line improvement in acuity compared to a one line deterioration in the 22 patients without any evidence of macular traction (regression coefficient $-0.25, \mathrm{CI}-0.05$ to $-0.43, \mathrm{p}=0.01$ ). The presence of SRF on OCT was associated with an adverse visual outcome (mean deterioration of $0.33 \log$ MAR, CI +0.08 to $+0.62, p=0.01)$. Only one of these four patients had macular traction; from this we hypothesise that in patients with DMO, SRF may have an exudative component as well as being a tractional phenomenon as suggested by Kaiser et al. ${ }^{38}$ We are not aware that SRF has previously been identified to be a potential adverse prognostic sign. No other a priori variables were found to influence the postoperative outcome.

A potential restriction to the VA improvement of patients is progression of cataract following vitreous surgery. We performed prospective Scheimpflug measurements on our RCT patients and found no statistically significant difference in progression of lens opacity in the first postoperative year. ${ }^{24}$

The findings of this study run parallel to those reported by Massin $e t \mathrm{al}^{7}$ but are at odds with the other prospective data on this subject. Included in these reports are the data recently reported by Recchia et al in which only $2 / 11$ patients had any OCT signs suggesting macular traction but mean VA improved from 20/352 to 20/119. ${ }^{34}$ Reasons for these differences are not immediately obvious but may include racial factors, disease duration and severity, extent of previous laser and macular ischaemia, a small and unconsciously biased sample on our part, and/or positive reporting bias on the part of other series.

We recognise the limited power of this study; however, our findings suggest that the benefits of vitrectomy for chronic DMO are limited to patients with clinical and/or OCT signs suggestive of traction. Macular detachment on OCT may additionally be an adverse predictive indicator.

\section{Authors' affiliations \\ S P Shah, London School of Hygiene and Tropical medicine, Keppel Street, London W1, UK \\ M Patel, D Thomas, D A H Laidlaw, St Thomas's Hospital, Lambeth Palace Road, London SEl 7EH, UK \\ S Aldington, Retinopathy Grading Centre, Division of Investigative Science, Imperial College London W12 ONN, UK \\ The authors have no commercial or proprietary interest in this article.}

Correspondence to: D Alistair H Laidlaw, Eye Department, St Thomas's Hospital, Lambeth Palace Road, London SEI 7EH, UK; allaidlaw@btinternet.com

Accepted for publication 29 August 2005 


\section{REFERENCES}

1 Lewis H, Abrams GW, Blumenkranz MS, et al. Vitrectomy for diabetic macular traction and edema associated with posterior hyaloidal traction. Ophthalmology 1992:99:753-9.

2 Harbour JW, Smiddy WE, Flynn HW Jr, et al. Vitrectomy for diabetic macular edema associated with a thickened and taut posterior hyaloid membrane. Am J Ophthalmol 1996;121:405-13.

3 Pendergast SD. Vitrectomy for diabetic macular edema associated with a taut premacular posterior hyaloid. Curr Opin Ophthalmol 1998;9:71-5.

4 Pendergast SD, Hassan TS, Williams GA, et al. Vitrectomy for diffuse diabetic macular edema associated with a taut premacular posterior hyaloid. Am J Ophthalmol 2000;130:178-86

5 Gandorfer A, Messmer EM, Ulbig MW, et al. Resolution of diabetic macular edema after surgical removal of the posterior hyaloid and the inner limiting membrane. Retina 2000;20:126-33.

6 Van Effenterre G, Guyot-Argenton C, Guiberteau B, et al. Macular edema caused by contraction of the posterior hyaloid in diabetic retinopathy. Surgical treatment of a series of 22 cases. J Fr Ophtalmol 1993;16:602-10.

7 Massin P, Duguid G, Erginay A, et al. Optical coherence tomography for evaluating diabetic macular edema before and after vitrectomy. Am J Ophthalmol 2003;135:169-77.

8 Tachi N, Ogino N. Vitrectomy for diffuse macular edema in cases of diabetic retinopathy. Am J Ophthalmol 1996;122:258-60.

9 Tachi N, Hashimoto Y, Ogino N. Cystotomy for diabetic cystoid macular edema. Doc Ophthalmol 1999;97:459-63.

10 Ikeda T, Sato K, Katano T, et al. Improved visual acuity following pars plana vitrectomy for diabetic cystoid macular edema and detached posterior hyaloid. Retina 2000;20:220-2.

11 Ikeda T, Sato K, Katano T, et al. Vitrectomy for cystoid macular oedema with attached posterior hyaloid membrane in patients with diabetes. Br J Ophthalmol 1999;83:12-14.

12 Otani T, Kishi S. A controlled study of vitrectomy for diabetic macular edema. Am J Ophthalmol 2002;134:214-19.

13 Otani T, Kishi S. Tomographic assessment of vitreous surgery for diabetic macular edema. Am J Ophthalmol 2000;129:487-94.

14 Yamamoto T, Hitani K, Tsukahara I, et al. Early postoperative retinal thickness changes and complications after vitrectomy for diabetic macular edema. Am J Ophthalmol 2003;135:14-19.

15 Yamamoto T, Akabane N, Takeuchi S. Vitrectomy for diabetic macular edema: the role of posterior vitreous detachment and epimacular membrane. Am J Ophthalmol 2001;132:369-77.

16 La Heii EC, Hendrikse F, Kessels AG, et al. Vitrectomy results in diabetic macular oedema without evident vitreo-macular traction. Graefes Arch Clin Exp Ophthalmol 2001;239:264-70

17 Giovannini A, Amato G, Mariotti C, et al. Optical coherence tomography findings in diabetic macular edema before and after vitrectomy. Ophthalmic Surg Lasers 2000;31:187-91.

18 Amino K, Tanihara H. Vitrectomy combined with phacoemulsification and intraocular lens implantation for diabetic macular edema. Jpn J Ophthalmol 2002;46:455-9.

19 Kalvodova B, Zahlava J. Results of vitrectomy in cystoid diabetic macular edema detected by optical coherence tomography. Cesk Slov Oftalmol 2002;58:224-32

20 Kojima T, Terasaki H, Nomura H, et al. Vitrectomy for diabetic macular edema: effect of glycemic control $(\mathrm{HbA}(1 \mathrm{c}))$, renal function (creatinine) and other local factors. Ophthalmic Res 2003;35:192-8.

21 Micelli Ferrari T, Cardascia N, Durante G, et al. Pars plana vitrectomy in diabetic macular edema. Doc Ophthalmol 1999;97:471-4.
22 Ndoye Roth PA, Grange JD, Haiji Z. [Diabetic cystoid macular edema and vitrectomy. Preliminary results: about 19 cases]. J Fr Ophtalmol 2003;26:38-46.

23 Rosenblatt BJ, Shah GK, Sharma S, et al. Pars plana vitrectomy with internal limiting membranectomy for refractory diabetic macular oedema without a taut posterior hyaloid. Graefes Arch Clin Exp Ophthalmol 2005;243:20-5.

24 Thomas D, Bunce C, Moorman C, et al. A randomised controlled feasibility trial of vitrectomy versus laser for diabetic macular oedema. Br J Ophthalmol 2005:89:81-6.

25 Kandonosono K, Itoh N, Ohno S. Perifoveal microcirculation before and after vitrectomy for diabetic cystoid macular edema. Am J Ophthalmol 2000;130:740-4

26 Dillinger $\mathbf{P}$, Mester U. Vitrectomy with removal of the internal limiting membrane in chronic diabetic macular oedema. Graefes Arch Clin Exp Ophthalmol 2004;242:630-7.

27 Avci R, Kaderli B, Avci B, et al. Pars plana vitrectomy and removal of the internal limiting membrane in the treatment of chronic macular oedema. Graefe's Arch Clin Exp Ophthalmol, 2004;242:845-52.

28 Jahn C, Topfner von Schutz K, Richter J, et al. Improvement of visual acuity in eyes with diabetic macular edema after treatment with pars plana vitrectomy. Ophthalmologica 2004;218:378-84.

29 Otani T. Tomographic findings of foveal hard exudates in diabetic macular edema. Am J Ophthalmol 2001;131:50-4.

30 Stefaniotou MI, Aspiotis MV, Kalogeropoulos CD. Vitrectomy results for diffuse DME with and without ILM removal. Eur J Ophthalmol 2004; 14:137-43.

31 Sato $Y$, Lee $Z$, Shimada $\mathrm{H}$. Vitrectomy for diabetic cystoid macular edema. Jpn J Ophthalmol 2002;46:315-22.

32 Tachi N. Vitrectomy for macular edema. J Jpn Soc Ophthalmic Surg 1994;7:407-14.

33 Giovannini, Amato G, Mariotti C, et al. Optical coherence tomography findings in diabetic macular edema before and after vitrectomy. Ophthalmic Surg Lasers 2000;31:187-91.

34 Recchia FM, Ruby AJ, Carvalho Recchia CA. Pars plana vitrectomy with removal of the internal limiting membrane in the treatment of persistent diabetic macular edema. Am J Ophthalmol 2005;139:447-54.

35 Yanyali A, Nohutcu AF, Horozoglu F, et al. Modified grid laser photocoagulation versus pars plana vitrectomy with internal limiting membrane removal in diabetic macular edema. Am J Ophthalmol 2005; 139:795-801.

36 Diabetic Retinopathy Study. Report number six. Design, methods and baseline results DRS Report Number seven. Modified Airlie House classification of Diabetic retinpathy. Prepared by the the Diabetic Retinopathy Study Research Group. Invest Ophthalmol Vis Sci 1981;21:1-226.

37 Early Treatment Diabetic Retinopathy Study Research Group. Fundus photographic risk factors for progression of diabetic retinopathy. ETDRS Report Number 12. Ophthalmology 1991;98:823-33.

38 Kaiser $\mathbf{P}$, Reimann CD, Sears JE, et al. Macular traction detachment and diabetic macular edema associated with posterior hyaloidal traction. Am J Ophthalmol 2001;131:44-9.

39 Gallemore RP, Jumper JM, McCuen BW, et al. Diagnosis of vitreoretinal adhesions in macular disease with optical coherence tomography. Retina 2000;20:115-20.

40 Haouchine B, Massin P, Gaudric A. The foveal cyst as the first step in macular hole formation. A prospective study by optical coherence tomography. Ophthalmology 2001;108:15-22.

41 Massin P, Vicaut E, Haouchine B, et al. Reproducibility of retinal mapping using optical coherence tomography. Arch Ophthalmol 2001;119:1135-42. 